\title{
ANALISIS FAKTOR-FAKTOR RISIKO TERJADINYA TB PARU PADA PASIEN DM TIPE 2 DI RS IBNU SINA MAKASSAR
}

\author{
Hermiaty Nasruddin ${ }^{1}$, Santriani Hadi ${ }^{2}$,dan Musdalifah Eka Pratiwi ${ }^{3}$ \\ ${ }^{I}$ Bagian IKM/IKK Fakultas Kedokteran Universitas Muslim Indonesia Makassar \\ ${ }^{2}$ Bagian Parasit Fakultas Kedokteran Universitas Muslim Indonesia Makassar \\ ${ }^{3}$ Mahasiswa Pre Klinik Fakultas Kedokteran Universitas Muslim Indonesia Makassar
}

\begin{abstract}
Abstrak
Latar Belakang : Peningkatan prevalensi DM, sebagai faktor risiko TB juga disertai dengan peningkatan prevalensi TB. Peningkatan kasus TB pada pasien DM terutama pada negara-negara berpenghasilan rendah-menengah, juga terjadi di Indonesia. Cukup banyak pasien DM yang mengalami $\mathrm{TB}$ dan hal tersebut meningkatkan morbiditas maupun mortalitas TB maupun DM. Metode Penelitian : Penelitian ini merupakan penelitian analitik deskriptif dengan pendekatan cross sectional dengan menggunakan teknik total sampling. Sampel yang digunakan berupa rekam medik dengan jumlah 60 sampel yang memenuhi kriteria inklusi dan ekslusi di RS Ibnu Sina Makassar pada tahun 2015-2016. Pengumpulan data dilakukan dengan mengambil data secara langsung pada bagian rekam medik RS Ibnu Sina Makassar. Analisa data menggunakan uji chi-square. Hasil Penelitian : Didapatkan subjek penelitian ini yaitu rekam medik pasien DM Tipe 2 di RS Ibnu Sina Makassar tahun 2015-2016 berjumlah 60 orang, dengan prevalensi kejadian TB Paru pada pasien DM Tipe 2 adalah 50\% dari jumlah sampelyang digunakan. Berdasarkan hasil analisis bivariat, didapatkan faktor resiko yang berpengaruh terhadap kejadian TB Paru adalah status gizi dan riwayat kontak TB. Setelah dilakukan analisis multivariat, faktor yang memiliki hubungan bermakna dengan TB Paru pada pasien DM Tipe 2 yaitu riwayat kontak TB (OR 145; p=0,000;[IK95\% 15,8-1325,3]). Kesimpulan : Hasil penelitian di RS Ibnu Sina Makassar tahun 2015-2016 didapatkan pasien DM Tipe 2 dengan komplikasi TB Paru berjenis kelamin wanita lebih banyak dibandingkan dengan pria dan terbanyak pada rentang usia 50-60 tahun. Faktor-faktor risiko yang berpengaruh terhadap kejadian TB Paru pada pasien DM Tipe 2 yaitu status gizi dan riwayat kontak TB Paru. Sedangkan faktor risiko kejadian TB pada pasien DM yang paling berpengaruh adalah riwayat kontak TB.
\end{abstract}

Kata Kunci : Tuberkulosis Paru, DM Tipe 2 
PENDAHULUAN

Tuberkulosis (TB) merupakan salah satu penyakit tertua yang menginfeksi manusia. Penyakit ini menjadi masalah kesehatan di seluruh dunia dan menyebabkan angka kematian yang tinggi. Penyakit ini disebabkan oleh Mycobacterium tuberculosis yang berbentuk batang, tidak membentuk spora, bersifat aerob dan tahan asam. TB umumnya terjadi pada paru, tetapi dapat pula menyerang organ lain pada sepertiga kasus. Walaupun telah mendapat pengobatan TB yang efektif, penyakit ini tetap menginfeksi hampir sepertiga populasi dunia, dan setiap tahunnya menimbulkan penyakit pada sekitar 8,8 juta orang, serta membunuh 1,6 juta pasiennya. Indonesia masih menempati posisi ke 5 di dunia untuk jumlah kasus TB. ${ }^{1-3}$

World Health Organization (WHO) menetapkan target pada tahun 2050 penurunan insiden TB sampai dengan 1 kasus per 1 juta penduduk. Kecenderungan penurunan kasus TB secara global belum mencapai target ini. ${ }^{3}$ Oleh karena itu, perlu dilakukan upaya tambahan untuk meningkatkan deteksi TB dan kesuksesan terapi melalui peninjauan pada populasi khusus dengan faktor risiko $\mathrm{TB}$, di antaranya DM. ${ }^{4}$

Dalam dua dekade terakhir terjadi peningkatan prevalensi DM, terutama DM tipe II. Hal ini disebabkan oleh perubahan gaya hidup, meningkatnya obesitas, dan berkurangnya aktivitas yang umumnya terjadi pada Negara-negara yang mulai mengalami industrialisasi. Peningkatan prevalensi DM, sebagai faktor risiko TB juga disertai dengan peningkatan prevalensi TB. Para ahli mulai memberi perhatian pada epidemiologi DM dan TB, terutama pada negaranegara berpenghasilan rendahmenengah, seperti Cina dan India yang mengalami peningkatan prevalensi DM tercepat dan memiliki beban TB tertinggi di dunia. ${ }^{2}$

Peningkatan kasus TB pada pasien DM juga terjadi di Indonesia. Cukup banyak pasien DM yang mengalami TB dan hal tersebut meningkatkan morbiditas maupun mortalitas TB maupun DM. Berdasarkan latar belakang diatas, penulis tertarik untuk mengidentifikasi “Analisis Faktor-Faktor Risiko Terjadinya TB Paru pada Pasien DM Tipe 2 di RS Ibnu Sina Makassar". 
METODE PENELITIAN

Jenis penelitian ini adalah analitik deskriptif dengan menggunakan pendekatan Cross Sectional Study yaitu menjelaskan tentang Analisis Faktor-Faktor Risiko Terjadinya TB Paru pada Pasien DM Tipe 2 di RS Ibnu Sina Makassar. Dilaksanakan pada tanggal 18-22 April 2017.

Populasi yang diambil dalam penelitian ini adalah semua pasien yang menderita DM Tipe 2 sekaligus TB paru di Rumah Sakit Ibnu Sina Makassar pada Tahun 2015-2016. Adapun sampel penelitian sama dengan populasi. Cara pengambilan sampel adalah dengan menggunakan teknik total sampling.
Penelitian ini dilakukan dengan melihat rekam medik pada pasien yang menderita DM Tipe 2 disertai TB Paru di Rumah Sakit Ibnu Sina Makassar pada tahun 2015-2016 yang merupakan objek utama dalam penelitian ini. Berdasarkan data rekam medik pasien DM Tipe 2 yang dikelompokkan menjadi yang mengalami komplikasi TB Paru dan tidak mengalami komplikasi TB Paru. Kemudian membandingkan bagaimana pengaruh faktor risiko dan faktor risiko apa yang paling berpengaruh menggunakan aplikasi SPSS 22 dengan teknik chi square atau Chi-Kuadran.

\section{HASIL PENELITIAN}

1. Distribusi frekuensi pasien DM Tipe 2 yang mengalami komplikasi TB Paru dan tidak mengalami komplikasi TB Paru di RS Ibnu Sina Makassar tahun 2015-2016.

\begin{tabular}{ccc}
\hline & N & \% \\
\hline Komplikasi TB Paru & 30 & 50 \\
Tanpa Komplikasi TB Paru & 30 & 50 \\
\hline Total & 60 & 100 \\
\hline
\end{tabular}

(Sumber: Rekam Medik RS Ibnu Sina Makassar tahun 2015-2016)

Berdasarkan tabel 1 diatas

dapat diketahui bahwa jumlah pasien

DM Tipe 2 yang mengalami

komplikasi TB Paru yaitu 30 orang
(50\%) dan jumlah pasien DM Tipe 2

yang tidak mengalami komplikasi TB

Paru yaitu 30 orang (50\%). 
2. Perbandingan jenis kelamin pasien DM Tipe 2 yang mengalami komplikasi TB Paru dan tidak mengalami komplikasi TB Paru di RS Ibnu Sina Makassar tahun 2015-2016.

\begin{tabular}{|c|c|c|c|c|c|c|c|}
\hline & \multicolumn{4}{|c|}{ Komplikasi TB Paru } & \multicolumn{2}{|c|}{ Total } & \multirow{2}{*}{$\mathrm{p}$-value } \\
\hline & $\mathrm{Ya}$ & $\%$ & Tidak & $\%$ & $\mathrm{~N}$ & $\%$ & \\
\hline Pria & 10 & 55,6 & 8 & 44,8 & 18 & 100 & \\
\hline Wanita & 20 & 47,6 & 22 & 52,4 & 42 & 70 & 0.573 \\
\hline Jumlah & 30 & 50 & 30 & 50 & 60 & 100 & \\
\hline
\end{tabular}

Tabel 2. merupakan hasil maka, keputusannya adalah $\mathrm{H}_{0}$ diterima, statistik inferensi. Berikut ini adalah yang berarti tidak terdapat pengaruh statistik uji hipotesis dari chi-square yang nyata (signifikan) variabel jenis text berdasarkan output di atas. kelamin terhadap kejadian TB Paru Ditetapkan tingkat signifikan 0.25 dan pada pasien DM Tipe 2 . p-value (0.573), karena p-value $>\alpha$

3. Perbandingan umur pada pasien DM Tipe 2 yang mengalami komplikasi TB Paru dan tidak mengalami komplikasi TB Paru di RS Ibnu Sina Makassar tahun 2015-2016.

\begin{tabular}{cccccccc}
\hline & \multicolumn{3}{c}{ Komplikasi TB Paru } & \multicolumn{3}{c}{ Total } & \multirow{2}{*}{ p-value } \\
& Ya & $\%$ & Tidak & $\%$ & $\mathrm{~N}$ & $\%$ & -ver \\
\hline <50 Tahun & 3 & 37,5 & 5 & 62,5 & 8 & 100 & \\
50-60 Tahun & 14 & 50 & 14 & 50 & 28 & 100 & \multirow{0}{*}{-717 } \\
>60 Tahun & 13 & 54,2 & 11 & 45,8 & 24 & 100 & \\
Jumlah & 30 & 50 & 30 & 50 & 60 & 100 & \\
\hline
\end{tabular}

(Sumber: Rekam Medik RS Ibnu Sina Makassar tahun 2015-2016, diolah dengan spss 22, 2017)

Tabel 3 merupakan hasil maka, keputusannya adalah $\mathrm{H}_{0}$ diterima, statistik inferensi. Berikut ini adalah yang berarti tidak terdapat pengaruh statistik uji hipotesis dari chi-square yang nyata (signifikan) variabel umur text berdasarkan output di atas. terhadap kejadian TB Paru pada pasien Ditetapkan tingkat signifikan 0.25 dan DM Tipe 2.

p-value (0.717), karena $p$-value $>\alpha$ 
4. Perbandingan status gizi pada pasien DM Tipe 2 yang mengalami komplikasi TB Paru dan tidak mengalami komplikasi TB Paru di RS Ibnu Sina Makassar tahun 2015-2016.

\begin{tabular}{cccccccc}
\hline & \multicolumn{3}{c}{ Komplikasi TB Paru } & \multicolumn{3}{c}{ Total } & \multirow{2}{*}{-value } \\
& Ya & $\%$ & Tidak & $\%$ & N & $\%$ & \\
\hline Kurang & 10 & 83,3 & 2 & 16,7 & 12 & 100 & \\
Normal & 20 & 41,6 & 28 & 58,3 & 48 & 100 & $\mathbf{0 . 0 3 5}$ \\
dan lebih & & & & & & & \\
Jumlah & 30 & 50 & 30 & 50 & 60 & 100 & \\
\hline (Sumber: Rekam Medik RS Ibnu Sina Makassar tahun 2015-2016, diolah dengan spss 22, 2017)
\end{tabular}

Tabel 4 merupakan hasil maka, keputusannya adalah $\mathrm{H}_{1}$ diterima, statistik inferensi. Berikut ini adalah yang berarti ada pengaruh yang nyata statistik uji hipotesis dari chi-square (signifikan) variabel status gizi text berdasarkan output di atas. terhadap kejadian TB Paru pada pasien Ditetapkan tingkat signifikan 0.25 dan DM Tipe 2. p-value (0.035), karena p-value $<\alpha$

5. Perbandingan riwayat merokok pada pasien DM Tipe 2 yang mengalami komplikasi TB Paru dan tidak mengalami komplikasi TB Paru di RS Ibnu Sina Makassar tahun 2015-2016.

\begin{tabular}{cccccccc}
\hline & \multicolumn{3}{c}{ Komplikasi TB Paru } & \multicolumn{3}{c}{ Total } & p-value \\
& Ya & $\%$ & Tidak & $\%$ & $\mathrm{~N}$ & $\%$ & \\
\hline Ada & 10 & 58,8 & 7 & 41,2 & 17 & 100 & \\
$\begin{array}{c}\text { riwayat } \\
\text { merokok }\end{array}$ & & & & & & & \\
$\begin{array}{c}\text { Tidak ada } \\
\text { riwayat } \\
\text { merokok }\end{array}$ & 20 & 46,5 & 23 & 53,5 & 43 & 100 & $\mathbf{0 . 3 9 0}$ \\
Jumlah & 30 & 50 & 30 & 50 & 60 & 100 & \\
\hline (Sumber: Rekam Medik RS Ibnu Sina Makassar tahun 2015-2016, diolah dengan spss 22, 2017)
\end{tabular}

Tabel 5 merupakan hasil maka, keputusannya adalah $\mathrm{H}_{0}$ diterima, statistik inferensi. Berikut ini adalah yang berarti tidak terdapat pengaruh statistik uji hipotesis dari chi-square yang nyata (signifikan) variabel text berdasarkan output di atas. riwayat merokok terhadap kejadian TB Ditetapkan tingkat signifikan 0.25 dan Paru pada pasien DM Tipe 2. p-value (0.390), karena p-value $>\alpha$ 
6. Perbandingan Lama Menderita DM pada pasien DM Tipe 2 yang mengalami komplikasi TB Paru dan tidak mengalami komplikasi TB Paru di RS Ibnu Sina Makassar tahun 2015-2016.

\begin{tabular}{cccccccc}
\hline & \multicolumn{3}{c}{ Komplikasi TB Paru } & \multicolumn{3}{c}{ Total } & \multirow{2}{*}{ p-value } \\
& Ya & $\%$ & Tidak & $\%$ & $\mathrm{~N}$ & $\%$ & \\
\hline$<1$ tahun & 2 & 40 & 3 & 60 & 5 & 100 & \\
1 1-5 tahun & 14 & 50 & 14 & 50 & 28 & 100 & \\
6-10 tahun & 8 & 50 & 8 & 50 & 16 & 100 & $\mathbf{0 . 9 6 2}$ \\
$>10$ tahun & 6 & 54,5 & 5 & 45,5 & 11 & 100 & \\
Jumlah & 30 & 50 & 30 & 50 & 60 & 100 & \\
\hline
\end{tabular}

(Sumber: Rekam Medik RS Ibnu Sina Makassar tahun 2015-2016, diolah dengan spss 22, 2017)

Tabel 6 merupakan hasil maka, keputusannya adalah $\mathrm{H}_{0}$ diterima, statistik inferensi. Berikut ini adalah yang berarti tidak terdapat pengaruh statistik uji hipotesis dari chi-square yang nyata (signifikan) variabel lama text berdasarkan output $\mathrm{di}$ atas. menderita DM terhadap kejadian TB Ditetapkan tingkat signifikan 0.25 dan Paru pada pasien DM Tipe 2. p-value (0.962), karena p-value $>\alpha$

7. Perbandingan riwayat kontak TB Paru pada pasien DM Tipe 2 yang mengalami komplikasi TB Paru dan tidak mengalami komplikasi TB Paru di RS Ibnu Sina Makassar tahun 2015-2016.

\begin{tabular}{cccccccc}
\hline & \multicolumn{3}{c}{ Komplikasi TB Paru } & \multicolumn{3}{c}{ Total } & p-value \\
& Ya & $\%$ & Tidak & $\%$ & N & $\%$ & \\
\hline $\begin{array}{c}\text { Ada riwayat } \\
\text { kontak TB Paru } \\
\quad \text { Tidak ada } \\
\text { riwayat kontak }\end{array}$ & 5 & 96,2 & 1 & 3,8 & 26 & 100 & \\
$\quad \begin{array}{l}\text { TB Paru } \\
\text { Jumlah }\end{array}$ & 30 & 50 & 30 & 50 & 60 & 100 & $\mathbf{0 . 0 0 0}$ \\
\hline Sumber: Rekam Medik RS Ibnu Sina Makassar tahun 2015-2016, diolah dengan spss 22, 2017)
\end{tabular}

Tabel 7 merupakan hasil maka, keputusannya adalah $\mathrm{H}_{1}$ diterima, statistik inferensi. Berikut ini adalah yang berarti ada pengaruh yang nyata statistik uji hipotesis dari chi-square (signifikan) variabel riwayat kontak TB text berdasarkan output di atas. Paru terhadap kejadian TB Paru pada Ditetapkan tingkat signifikan 0.25 dan pasien DM Tipe 2.

p-value (0.000), karena p-value $<\alpha$ 


\section{Perbandingan kategori HbA1C pada pasien DM Tipe 2 yang mengalami komplikasi TB Paru dan tidak mengalami komplikasi TB Paru di RS Ibnu Sina Makassar tahun 2015-2016.}

\begin{tabular}{cccccccc}
\hline & \multicolumn{3}{c}{ Komplikasi TB Paru } & \multicolumn{3}{c}{ Total } & \multirow{2}{*}{-value } \\
& Ya & $\%$ & Tidak & $\%$ & $\mathrm{~N}$ & $\%$ & \\
\hline$<6,5$ & 2 & 100 & 0 & 0 & 2 & 100 & \\
$6,5-9$ & 7 & 46,7 & 0 & 53,3 & 15 & 100 & \multirow{2}{*}{$\mathbf{0 . 3 5 2}$} \\
$>9$ & 21 & 48,8 & 22 & 51,2 & 43 & 100 & \\
Jumlah & 30 & 50 & 30 & 50 & 60 & 100 & \\
\hline
\end{tabular}

(Sumber: Rekam Medik RS Ibnu Sina Makassar tahun 2015-2016, diolah dengan spss 22, 2017)

Tabel 8 merupakan hasil mendapatkan terdapat hubungan antara statistik inferensi. Berikut ini adalah jenis kelamin pria $\mathrm{p}<0,01$ dengan statistik uji hipotesis dari chi-square terjadinya TB pada pasien DM. Jenis text berdasarkan output di atas. kelamin pria memiliki aOR 5.50 Ditetapkan tingkat signifikan 0.25 dan [IK95\%: 1,70-17,85]) lebih mudah p-value (0.352), karena p-value $>\alpha$ menjadi $\mathrm{TB}^{28}$.

maka, keputusannya adalah $\mathrm{H}_{0}$ diterima,

\section{Umur}

yang berarti tidak terdapat pengaruh

Data Uji regresi logistik pada yang nyata (signifikan) variabel penelitian ini menunjukkan tidak kategori HbA1C terhadap kejadian TB terdapat hubungan antara kategori Paru pada pasien DM Tipe 2.

umur dengan kejadian TB Paru $(\mathrm{p}=0,717)$. Alisjahbana $\mathrm{dkk}^{29}$

\section{PEMBAHASAN}

\section{Jenis Kelamin}

mengaitkan usia yang lebih tua pada pasien DM dengan TB. Penderita DM

Data uji regresi logistik di atas usia 40 tahun meningatkan menunjukkan tidak terdapat hubungan antara jenis kelamin dengan terjadinya risiko TB. Frekuensi BTA-positif yang lebih tinggi dilaporkan pada penderita TB Paru pada penelitian ini $(\mathrm{p}=0,573)$. DM berusia 60 tahun atau lebih karena Pria penderita DM umumnya dianggap usia tersebut termasuk usia yang lebih berisiko TB dibandingkan wanita, berisiko terhadap penyakit ${ }^{29}$. tetapi alasannya belum jelas, kemungkinan berhubungan dengan kebiasaan merokok. Zhao $\mathrm{dkk}^{28}$ 
Pada hasil uji regresi logistik didapatkan status gizi kurang berisiko 7 kali lebih besar untuk menderita TB daripada pasien dengan status gizi normal dan lebih. (Aor 7 [IK95\%: 1,38-25,48]). Zhao $\mathrm{dkk}^{28}$ juga mendapatkan hasil yang serupa yaitu terdapat hubungan antara status gizi dengan TB pada pasien DM $(\mathrm{P}<0,05)$. Berat badan normal dan lebih (aOR 0,15 [IK95\%: 0,04-0,56]) lebih kecil kemungkinan memiliki TB dibanding mereka dengan berat badan rendah ${ }^{28}$. Risiko terhadap TB tersebut diakibatkan oleh malnutrisi yang cenderung terjadi bersama-sama dengan kemiskinan, stress dan merokok, sehingga sulit untuk mengisolasi komponen gizi. Malnutrisi juga bisa akibat dari penyakit TB atau mendahului perkembangan TB. Di Indonesia, TB dikaitkan dengan malnutrisi dan $\mathrm{DM}^{29}$.

\section{Riwayat Merokok}

Pada penelitian ini didapatkan analisis bahwa merokok tidak memiliki hubungan dengan terjadinya TB Paru pada pasien DM $(\mathrm{p}=0,401)$. Berdasarkan beberapa referensi, bahwa rokok dapat melemahkan sistem imunitas tubuh sehingga meningkatkan risiko untuk terinfeksi TB Paru.
Perokok dua kali lebih mungkin untuk menjadi TB aktif dibandingkan dengan orang yang tidak pernah merokok dapat mengurangi risiko menderita TB Paru $^{31,32}$. Suatu penelitian menunjukkan berhenti merokok dapat menurunkan kematian TB hampir dua pertiga atau hampir sama pada mereka yang tidak merokok dibandingkan dengan mereka yang terus merokok ${ }^{32}$.

\section{Lama Menderita DM}

Menurut hasil analisis bivariat, tidak terdapat hubungan yang bermakna antara lama menderita DM dengan kejadian TB Paru $(p=0,962)$. Ditemukan jumlah penderita TB paling banyak pada pasien yang lama sakit DM-nya 1-5 tahun. Berbeda dengan penelitian Amare $\mathrm{dkk}^{30}$ juga mendapatkan hubungan antara lama DM >10 tahun sebanyak 17\% sedangkan penderita DM kurang dari 10 tahun hanya 5\%. Jali $\mathrm{dkk}^{27}$ menemukan prevalensi TB paling tinggi $(42,8 \%)$ adalah subjek yang menderita DM lebih dari 10 tahun. Lama menderita DM diduga memperburuk daya tahan tubuh pasien DM da merupakan predisposisi TB pada semua kelompok umur ${ }^{33,34}$. Sejalan dengan penelitian Zhao $\mathrm{dkk}^{28} \mathrm{di}$ Cina menemukan tidak terdapat 
hubungan yang signifikan antara lama menderita DM dengan kejadian TB Paru. Zhao $\mathrm{dkk}^{28}$ menbagi rentang lama menderita DM menjadi <1 tahun, 1-5 tahun dan $>10$ tahun.

Lama menderita DM pada penelitian ini kemungkinan tidak sesuai dengan lama menderita DM yang sebenarnya. Gejala DM sering tidak khas sehingga pasien tidak meyadari bahwa telah menderita DM. Gejala pada DM yang sudah lama dan menimbulkan gejala yang parah membuat pasien berobat ke dokter. Diabetes melitus dan TB sering muncul bersamaan, nampaknya inilah yang menyebbakan mengapa pasien yang menderita $\mathrm{DM} \pm 1$ tahun sudah terdiagnosis TB ditambah lagi di Indonesia banyak penderita TB laten ${ }^{35}$.

\section{Riwayat Kontak TB}

Penelitian ini mendapatkan hubungan yang bermakna antara riwayat kontak TB paru pada pasien DM Tipe 2 dengan subjek yang memiliki riwayat kontak penderita $\mathrm{TB}$ paru berisiko 145 kali lebih besar (aOR 145; [IK95\% :15,8-1325,3]). Penelitian Amare $\mathrm{dkk}^{30}$ mendapatkan 28 subjek yang memiliki riwayat kontak erat dengan penderita TB aktif dan 197 subjek yang tidak terdapat riwayat kontak serta menyatakan terdapat hubungan antara riwayat dengan penderita TB dengan terjadinya TB paru pada penderita DM (aOR 9,4[IK95\%: 1,882-48,50]). Berbeda dengan hasil penelitian Zhao $\mathrm{dkk}^{30}$ yang menunjukkan tidak terdapat hubungan kontak erat keluarga yang menderita TB dengan terjadinya TB. Kontak dengan penderita memungkinkan risiko penularan TB melalui droplet.

\section{Kategori HbA1C}

Pada penelitian tidak ditemukan adanya hubungan bermakna antara kadar HbA1C dengan TB paru pada pasien DM ( $\mathrm{p}=0,352)$. Berbeda dengan penelitian oleh Park $\mathrm{dkk}^{36}$ memiliki distribusi frekuensi 74 subjek $(59,7 \%)$ dengan DM tidak terkontrol (HbA1C $\geq 7,0 \%), 25$ subjek (20,2\%) dengan DM terkontrol $(\mathrm{HbA} 1 \mathrm{C}<7 \%)$ dan tidak terdapat data $\mathrm{HbA1C}$ pada 25 subjek (20,2\%). Rerata pengelolaan DM pada berbagai penelitian tidak mencapai target terapi (DM terkontrol). Kemungkinan penentu yang paling penting perkembangan TB adalah tingkat keterkontrolan dari DM itu sendiri. Berbeda dari hasil penelitian ini yang dimungkinkan karena minimnya jumlah sampel yang 
digunakan, suatu penelitian menunjukkan peningkatan risiko TB paru BTA-positif telah dibuktikan pada kadar HbA1C sebesar 7\% atau lebih, didukung pula oleh penelitian Leung $\mathrm{dkk}^{34}$ bahwa subjek DM dengan A1c $<7 \%$ tidak meningkatkan risiko $\mathrm{TB}$ Paru.

\section{KESIMPULAN}

Faktor-faktor risiko yang berpengaruh terhadap kejadian TB Paru pada pasien DM Tipe 2 yaitu status gizi dan riwayat kontak TB Paru, sedangkan faktor-faktor risiko lainnya yang tidak berpengaruh diantaranya jenis kelamin, umur, riwayat merokok, lama menderita DM Tipe 2, serta kategori HbA1C.

\section{DAFTAR PUSTAKA}

1. Raviglione MC, O'Brien RJ. Tuberculosis. Dalam: Fauci AS, Braunwald E, Hasper DL, Hauser SL, Longo DL, Jameson $\mathrm{JL}$, et al . penyunting. Harrison's Principles of Internal medicine. Edisi ke-17. USA: The McGraw-Hill Companies, Inc.; 2008.h.1006-20.

2. Jeon CY, Murray MB. Diabetes mellitus increases the risk of active Tuberculosis: a systematic review of 13 observational studies. PLoS Med [online] 2008 [cited 2016 june 16];5(7):11p. Diunduh dari: http://www.plosmedicine.org.
3. Perhimpunan Dokter Paru Indonesia. 2006. Tuberkulosis: Pedoman Diagnosis dan Penatalaksanaan di Indonesia. Jakarta: Perhimpunan Dokter Paru Indonesia.

4. Perkumpulan Endokrin Indonesia. Konsensus Pengelolaan dan Pencegahan Diabetes Mellitus tipe 2 di Indonesia. WHO Global Tuberculosis control: WHO report. [Online] 2011. [Cited 2016 June 16]. Availablefrom:http://www.who. int/tb/publications/global_report /2011/en/index.html.

5. Kementerian Kesehatan RI. 2012. Direktorat Jenderal Pengendalian penyakit Dan Penyehatan Lingkungan. Jakarta

6. Perkumpulan Endokrinologi Indonesia. 2011. Konsensus pengelolaan dan pencegahan diabetes melitus tipe 2 di Indonesia. Jakarta: PB PERKENI.

7. Wild S, Roglic G, Green A, Sicree R, King H.Global prevalence of Diabetes:estimates for the year 2000 and projections for 2030. Diabetes Care .2004;27:104753

8. World Health Organization. World Health Statistic. 2011. [online] 2011 [cited][2016june16].http://www .who.int/gho/publications/world _health_statistics/EN_WHS201 1_Full/pdf

9. Diabetes Association., 2012. Diagnosis and Classification of Diabetes Mellitus. Diabetes Care volume 35 Supplement I.

10. Suyono S. Diabetes melitus di Indonesia. Dalam : Sudoyo AW, 
Setyohadi B, Alwi I, 17. Departemen Kesehatan Simadibrata M, Setiati S. Buku Ajar Ilmu Penyakit Dalam. Edisi 4. Jakarta: Pusat Penerbitan Departemen Ilmu Penyakit Dalam FKUI; 2006. hlm.1874-8.

11. Powers AC. Diabetes mellitus. In: Fauci AS, Braunwald E, Kasper DL, Hauser SL, Longo DL, Jameson JL. Harrison's Principles of Internal Medicine. 17th Edition. United States: The McGraw-Hill Companies; 2008. hal2275-304

12. Tapp R, Shaw J, Zimmet P. Complications of Diabetes. Dalam: Gan D, Allgot B, King $\mathrm{H}$, Lefèbvre $\mathrm{P}$, Mbanya JC, Silink M, penyunting. Diabetes Atlas. Edisi ke-2. Belgium: International Diabetes Federation; 2003:h.72-112)

13. Sjahrurachman, A., 2010, "Diagnosis "Multi Drug Resistant Mycobacterium" Tuberkulosis", Perkumpulan Pemberantasan Tuberkulosis Indonesia (Ed.), Jurnal Tuberkulosis Indonesia.

14. Perhimpunan Dokter Paru Indonesia 2006. Tuberkulosis: Pedoman Diagnosis dan Penatalaksanaan di Indonesia http://www.klikpdpi.com/konse nsus/tb.tb.html (diakses tanggal 16 Juni 2016).

15. Perhimpunan Dokter Paru Indonesia. 2011. Pedoman Diagnosis \& Penatalaksanaan Tuberkulosis di Indonesia. Jakarta

16. Werdani, Retno Asti. 2009. Patofisiologi, Diagnosis, Klasifikasi Tuberkulosis Jurnal Departemen Ilmu Kedokteran Komunitas, Okupasi dan Keluarga. FKUI. Jakarta

Republik Indonesia, 2008. Pedoman Nasional Penanggulangan Tuberkulosis. Edisi 2. Cetakan II. Jakarta: Departemen Kesehatan Republik Indonesia

18. Kemenkes RI. 2011. Strategi Nasional Pengendalian TB di Indonesia 2010-2014.Jakarta; Kementerian Kesehatan RI.

19. Amin, Z.,Bahar, A.,2006. Ilmu Penyakit Dalam Jilid II.Edisi IV. Jakarta :Fakultas Kedokteran Universitas Indonesia.

20. Masniari Poeloengan, Iyep Komala dan Susan M Noor. 2004; Bahaya penanganan Tuberculisis. Dalam Lokakarya Penyakit Zoonosis, Balai Penelitian Veteriner Bogor.

21. World Health Organization (WHO). 2010. Global Tuberculosis Report 2010. Switzerland.

22. Restrepo BI. Convergence of the tuberculosis and diabetes epidemics: Renewal of old acquaintances. Clin Infect Dis. 2007; 45:436-8.

23. Ramamurti T. Pathology of mycobacterial infection in diabetes. Int J Diab Dev Ctries. 1999; 19: 56-60.

24. World Health Organization. Tuberculosis and diabetes. [Online]. 2011 [Cited 2016 June 16]. Available from URL: http://www.who.int/tb/publicati ons/ diabetes_tb.pdf.

25. 7 Ullah H, Iqbal Z, Ullah Z, Mahboob A, Rehman M. Frequency of Pulmonary Tuberculosis in patients presenting with Diabetes. [Online] 2013. [Cited 2013 
December 6]. Available from: http://

www.researchgate.net/publicati on/257061676

frequency_of_pulmonary_tuber culosis_in_patients_ presenting_with_diabetes? $\mathrm{ev}=\mathrm{p}$ ubfeed_inst.

26. Amin S, Khattak MI, Shabbier G, Wazir MN. Frequency of Pulmonary Tuberculosis in patient with Diabetes Mellitus. Gomal Journal of Medical Sciences. 2011;9(6):163-5.

27. Jali MV, Mahishale VK, Hiremath MB. Bidirectional screening of Tuberculosis patients for Diabetes mellitus and diabetes patients for Tuberculosis. Diabetes Metab J. 2013;37(4):291-5.

28. Zhao W, Shi L, Fonseca, He J, Shao D, Zhao J, Chen QM, Yin A. Screening patients with type 2 Diabetes for active Tuberculosis in communities of China. Diabetes care. 2013;36:e159-60.

29. Wulandari DR, Yani Jane Sugiri YJ, Diabetes mellitus dan permasalahannya pada infeksi Tuberkulosis. J Respir Indo. 2013;33:126-34.

30. Amare H, Gelaw A, Anagaw B, Gelaw B. Smear posi- tive Pulmonary Tuberculosis among diabetic patients at the Dessie referral hospital, Northeast Ethiopia. Infectious Diseases of Poverty. 2013;2(6):2-6.

31. Bates MN, Khalakdina A, Pai M. Risk of Tuberculosis from exposure to tobacco smoke: a systematic review and metaanalysis. Archives of Internal Medicine. 2007;167:335-42.

32. Slama K, Chiang C-Y, Enarson DA. Tobacco and Tuberculosis: A qualitative systematic review and meta-analysis. International Journal of Tuber-culosis and Lung Disease. 2007;11(10):1049-61.

33. Wen CP. The reduction of Tuberculosis risks by smoking cessation. BMC Infectious Diseases. 2010;10:156.

34. Leung CC, Lam TH, Chan WM, Yew WW, Ho KS, Leung GM, et al. Diabetic control and risk of Tuberculosis: a cohort study. Am J Epidemiol. 2008;167:1486-94.

35. Guptan A, Shah A. Tuberculosis and Diabetes: an appraisal. Indian $\mathbf{J}$ Tuberc. 2000;47:3-8.

36. Park SW, Shin Jw, Kim JY, Park IW, Choi BW, Choi JC, et al. The effect of diabetic control status on the clinical features of Pulmonary Tuberculosis. Eur J Clin Microbiol Infect Dis. 2012;31:1305-10. 